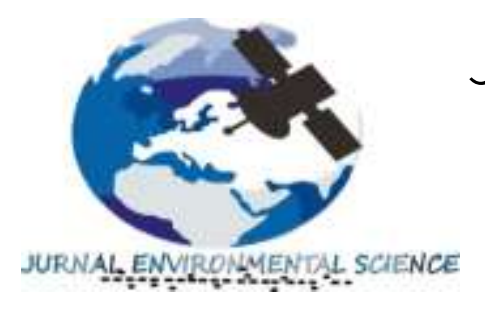

Jurnal Environmental Science

Volume 2 Nomor 2 April 2020

p-ISSN : 2654-4490 dan e-ISSN : 2654-9085

Homepage at : ojs.unm.ac.id/JES

E-mail :jes@unm.ac.id

\title{
IDENTIFIKASI DAN PEMETAAN LAHAN KRITIS DENGAN MENGGUNAKAN TEKNOLOGI SISTEM INFORMASI GEOGRAFIS (STUDI KASUS DAS JENERAKIKANG SUB DAS JENEBERANG KABUPATEN GOWA SULAWESI SELATAN
}

\author{
Rezki Amaliyah ${ }^{1}$, Ramli Umar ${ }^{2}$, Nasiah $^{3}$ \\ Jurusan Geografi, Fakultas Matematika dan Ilmu Pengetahuan Alam, \\ Universitas Negeri Makassar, Indonesia. \\ Email: reskiamaliyah12@gmail.com ${ }^{1}$
}

\begin{abstract}
The increasein Population effected on increase land requirements that force the people to convert forest land into residental land which had an impact on the declining qulity of the environtment causing the land to be a critical. The objectives of this Research are: (1) to find out factors that affect the class of critical land (2) to find out the class of critical land (3) to find out contermeasures of critical land. The object of this study is land of DAS Jenerakikang. Primary data used include slope, soil structure, soil texture, effektive depth of soil, land management and land use. Secondary data used include DEM data, Citra Landsat-8, rainfall data, produktivity of land. The type of this research is deskriptif eksploratif with the analytical method used is the skoring analysis method to identifity the class of critical land. The result of the study show there are 4 factors that affect the class of critical land are topography, soil, erosion, and vegetation. There are 4 categories of critical land specifically class of critical land with an areal 32,02 hectares, class of rather critical land with an areal 2.734,1 hectares, class of potential critical land with an areal 1.088,8 hectares ang class of ncritical land with an areal 56,229 hectares. Countermesures of critical land make us of physical-mechanic with application terracing and biological/vegetative with application multiple cropping.
\end{abstract}

Keywords: critical land, DAS Jenerakikang

\begin{abstract}
ABSTRAK
Penambahan jumlah penduduk mengakibatkan terjadinya peningkatan kebutuhan lahan yang memaksa masyarakat melakukan alih fungsi lahan hutan menjadi lahan pemukiman yang berdampak pada menurunnya kualitas lingkungan sehingga menyebabkan lahan tersebut menjadi kritis. Tujuan dari penelitian ini adalah: (1) Untuk mengetahui faktor yang mempengaruhi tingkat kekritisan lahan (2) Untuk mengetahui tingkat kekritisan lahan (3) Untuk mengetahui upaya penanggulangan lahan kritis. Objek penelitian ini yaitu Lahan di DAS Jenerakikang. Data primer yang digunakan meliputi data kemiringan lereng, struktur tanah, tekstur tanah, kedalaman efektif tanah, manajemen lahan dan data penggunaan lahan. Data sekunder yang digunakan meliputi data DEM, Citra Landsat-8, data curah hujan, produktivitas lahan. Jenis penelitian ini merupakan jenis penelitian deskriptif eksploratif dengan metode analisis yang digunakan yaitu metode skoring untuk mengidentifikasi tingkat kekritisan lahan. Hasil penelitian menunjukkan bahwa terdapat 4 faktor yang berpengaruh terhadap tingkat kekritisan lahan yakni topografi, tanah, erosi dan vegetasi. Terdapat 4 kategori lahan kritis yakni tingkat lahan kritis dengan luas 32,02 Ha tingkat lahan agak kritis dengan luas 2.734,1 Ha, tingkat lahan kritis potensial kritis dengan luas 1.088,8 Ha dan tingkat lahan tidak kritis dengan luas 56,229 Ha. Upaya penanggulangan lahan kritis menggunakan metode fisik-mekanik dengan penerapan terasering dan metode biologis/vegetatif dengan penerapan multiple Cropping.
\end{abstract}

Kata Kunci: Lahan Kritis, DAS Jenerakikang 


\section{PENDAHULUAN}

Peningkatan pembangunan dan pertumbuhan ekonomi seiring dengan pertambahan penduduk mengakibatkan tekanan penduduk pada lahan non pertanian. Tekanan penduduk terhadap lahan memaksa petani untuk menggarap lahan marginal, seperti tanah miring di tepi sungai, lereng bukit, dan gunung yang curam serta menyerobot lahan kehutanan (Argo, 2014). Perubahan fungsi lahan yang terjadi di sebagian besar wilayah, yaitu dari hutan ke lahan pertanian dan dari lahan pertanian ke pemukiman berdampak pada penurunannya kualitas lingkungan dan hal ini akan mengakibatkan lahan kritis (Renyut $d k k, 2018$ ).

DAS Jeneberang merupakan salah satu DAS Prioritas Nasional sebagaimana tercantum dalam Surat Keputusan bersama Menteri Dalam Negeri, Menteri Kehutanan dan Menteri Pekerjaan Umum No. 19 tahun 1984, No. 059/Kpts-II/1985 dan No. 124/Kpts/1984 yang dalam pengelolaannya perlu mendapat perhatian khusus (Sylviani, 2010). Salah satu Sub DAS yang ada di DAS Jeneberang yang berpotensi mengalami kekritisan lahan yakni Sub DAS Jenerakikang. DAS Jenerakikang merupakan Sub DAS yang berbatasan dengan DAS Maros dan DAS Tallo disebelah utaranya, DAS Jeberang disebelah timur dan baratnya, dan Sub DAS Malino disebelah selatannya. Sub DAS ini meliputi dua kecamatan yakni kecamatan parangloe dan kecamatan tinggi moncong, dengan luas wilayah 4.203,14 $\mathrm{Ha}$, total panjang sungainya mencapai $90,48 \mathrm{~km}$ (Peta Sub DAS Jenerakikang). Sub DAS Jenerakikang termasuk kedalam wilayah DAS Jeneberang yang dinyatakan berstatus kritis oleh Lembaga Wahana Lingkungan Hidup (WALHI) Sulawesi Selatan (Fatir, 2019).

Hasil riset yang dilakukan Lembaga Wahana Lingkungan Hidup (WALHI) Sulawesi Selatan pasca bencana memperlihatkan massifnya kerusakan kawasan hutan di Kabupaten Gowa. Tim Walhi mencatat, dari total luas area DAS Jeneberang sebesar 78.480.000 ha, luas area serapan air (area hutan serapan) tersisa saat ini hanya tinggal 16,8 persen. Sementara sisanya, sebanyak 83,2 persen telah digunakan sebagai kawasan non hutan dengan rincian 28,3 persen untuk persawahan; 41,2 persen untuk pertanian holtikultura; 8,9 persen sebagai pemukiman penduduk dan 1,3 persen Waduk BiliBili, serta 3,5 persen untuk aktivitas lainnya. Dari hasil penelitian tersebut DAS Jeneberang, dinyatakan berstatus kritis dan bisa mengancam keselamatan warga (Fatir, 2019).

Dari realita yang terjadi di Sub DAS Jenerakikang DAS Jeneberang, penulis tertarik untuk melakukan penelitian tentang "Pemetaan Tingkat Kekritisan Lahan di DAS Jenerakikang, Sub DAS Jeneberang, Kabupaten Gowa Provinsi Sulawesi Selatan”.

\section{METODE}

Lokasi penelitian dikhususkan pada DAS Jenerakikang, Sub DAS Jeneberang, Kabupaten Gowa, Provinsi Sulawesi Selatan yang terletak pada koordinat $5^{\circ} 12^{\prime} 00^{\prime \prime} \mathrm{LS}-5^{\circ} 16^{\prime} 00^{\prime \prime} \mathrm{LS}$ dan antara $119^{\circ} 40$ '00” BT - $119^{\circ} 48^{\prime} 00^{\prime \prime}$ BT. berbatasan dengan DAS Tallo di sebelah Utara, Sub DAS Maros di sebelah Timur, DAS Malino di sebelah Selatan dan Sungai Induk Jeneberang di sebelah Barat. Penelitian dilaksanakan pada bulan April 2019.

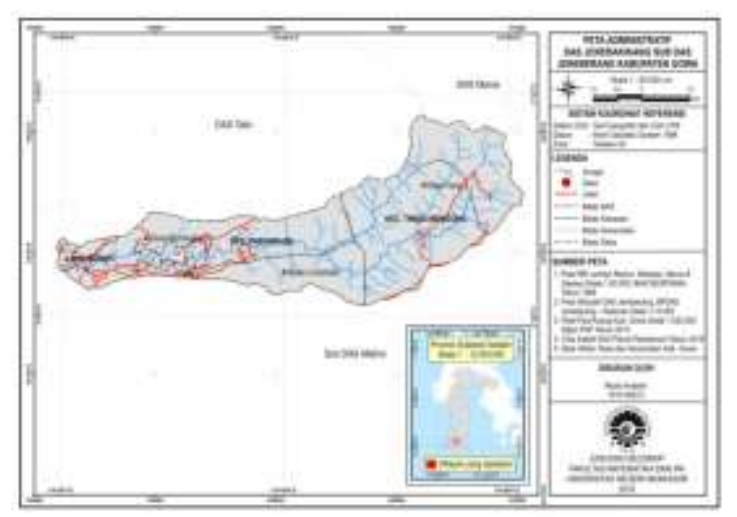

Gambar 1 Peta DAS Jenerakikang

Data yang digunakan dalam penelitian ini terdiri dari data primer dan data sekunder. Data primer diperoleh melalui survei lapangan dengan pengambilan contoh tanah dan pengambilan data berupa kemiringan lereng, struktur tanah, tekstur tanah, kedalaman efektif tanah manajemen lahan dan data penggunaan lahan serta dokumentasi sebagai verifikasi dan validasi untuk mengecek kebenaran, ketepatan dan kenyataan di lapangan. Data sekunder yang diperoleh dari berbagai sumber termasuk studi pustaka, koordinasi dan konsultasi dengan berbagai instansi terkait lahan kritis berupa data dari DEMNAS.com, USGS, data dari BPS Kabupaten Gowa dan Dinas Pertanian Provinsi Sulawesi 
Selatan, data dari BPDAS Jeneberang, data dari Dinas PU Direktorat Sumber Daya Air bagian Hidrologi dan Kualitas Air BBWS - PJ dan instansi lain yang berkaitan dengan data yang diperlukan.

Data yang digunakan dalam penelitian ini berupa data primer dan data sekunder. Data primer berupa pengukuran data di lapangan dan hasil laboratorium dari sampel tanah yang terdiri dari sampel tanah yang terdiri dari permeabilitas tanah, struktur tanah, tekstur tanah, berat volume tanah serta kandungan bahan organik yang nantinya digunakan untuk menentukan nilai erodibilitas tanah dan nilai erosi yang masih diperbolehkan (EDP). Sedangkan data sekunder berupa data Citra Landsat-8 Tahun Perekaman Bulan Maret Tahun 2017, Citra Satelit Perekaman SAS Planet, eta Rupa Bumi Indonesia Skala 1: 50.000 lembar Sapaya, Malakaji, Maros dan Malino., Peta Kemiringan Lereng DAS Jenerkikang Skala 1: 85.000, Peta Jenis Tanah DAS Jenerakikang Skala 1: 85.000, Peta Penggunaan Lahan DAS Jenerakikang Skala 1: 85.000, Peta Satuan Lahan DAS Jenerakikang Skala 1: 85.000, Peta Penentuan Titik Loksi Penelitian DAS Jenerakikang Skala 1: 85.000, Data curah hujan tiap stasiun DAS Jeneberang 10 tahun terakhir, Data Produktivitas Pertanian Kabupaten Gowa tahun 2018, Data Manajemen Lahan Kabupaten Gowa tahun 2018. Peralatan yang digunakan antara lain abney level, GPS, cangkul, sekop dan linggis, roll meter, pisau lapangan, kantong sampel, alat tulis menulis, kamera digital dan seperangkat komputer yang dilengkapi dengan softwere: ArcGIS, Michrosoft Word, Michrosoft Excel.

\section{Analisis Data}

Adapun teknik analisis data yang digunakan adalah teknik kartografis, yaitu dengan menggunakan sistem tumpang susun (overlay) beberapa peta (peta penggunaan lahan, peta tingkat bahaya erosi, Peta kemiringan lereng dan peta kelas produktivitas) untuk mendapatkan peta lahan kritis yang nantinya akan dianalisis faktor penyebab dan sebaran lahan kritis di DAS Jenerarikang, Sub DAS Jeneberang Kabupaten Gowa.

Penyusunan data spasial berupa penskoran dan pembobotan tiap parameter penentu lahan kritis sesuai Peraturan Peraturan Direktur Jenderal Bina Pengelolaan Daerah Sungai dan Perhutanan Sosial Nomor : P.4/V-SET/2013 tentang Tata Petunjuk Teknis Penyusunan Data Spasial Lahan Kritis. Berikut uraian metode penyusunan data spasial untuk setiap parameter penentuan lahan kritis :

1. Penutupan Lahan

Kondisi tutupan lahan diklasifikasikan berdasarkan tingkat kerapatan tajuk yang dari hasil klasifikasi tutupan lahan Landsat 8 menggunakan metode transformasi NDVI.

$$
N D V I=\frac{\text { Band } 5-\text { Band } 4}{\text { Band } 5+\text { Band } 4}
$$

Selanjutnya hasil klasifikasi diberi skor sesuai dengan kelas kerapatan vegetasi kemudian dilakukan pembobotan. Klasifikasi penskoran dan pembobotan kerapatan vegetasi seperti pada Tabel 1.

Tabel 1. Klasifikasi dan Skoring Penutupan Lahan

\begin{tabular}{cccc}
\hline Penutupan Lahan & $\begin{array}{c}\text { Persentase Penutupan } \\
\text { Tajuk }(\%)\end{array}$ & Skor & $\begin{array}{c}\text { Skor x Bobot } \\
(29)\end{array}$ \\
\hline Sangat Baik & $>80$ & 5 & 143 \\
Baik & $61-80$ & 4 & 114 \\
Sedang & $41-60$ & 3 & 86 \\
Buruk & $21-40$ & 2 & 57 \\
Sangat Buruk & $<20$ & 1 & 29 \\
\hline
\end{tabular}

Sumber: Peraturan Peraturan Direktur Jenderal Bina Pengelolaan Daerah Sungai dan Perhutanan Sosial Nomor : P.4/V-SET/2013

2. Kemiringan Lereng

Peta kelerengan diberi skor sesuai dengan kelas lerengnya kemudian harus dikonversi ke bentuk raster selanjutnya dilakukan pembobotan. Klasifikasi penskoran dan pembobotan kelerengan seperti pada Tabel 2. 
Tabel 2. Klasifikasi dan Skoring Kemiringan Lereng

\begin{tabular}{cccc}
\hline Kelas Lereng & Besaran/Deskripsi (\%) & Skor & Skor x Bobot (24) \\
\hline Dasar & $<8$ & 5 & 120 \\
Landai & $8-15$ & 4 & 96 \\
Agak Curam & $16-25$ & 3 & 72 \\
Curam & $26-40$ & 2 & 48 \\
Sangat Curam & $>40$ & 1 & 24
\end{tabular}

Sumber: Peraturan Direktur Jenderal Bina Pengelolaan Daerah Sungai dan Perhutanan Sosial

Nomor: P.4/V-SET/2013

3. Erosivitas Hujan

Hujan memiliki korelasi yang tinggi dengan terjadinya erosi. Indeks erosivitas hujan dihitung dengan rumus Lenvain (1975) dalam Indrihastuti (2016) sebagai berikut:

Dimana:

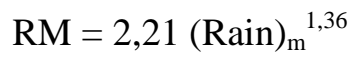

$$
\begin{array}{ll}
\mathrm{RM} & =\text { Erosivitas hujan bulanan } \\
(\text { Rain })_{\mathrm{m}} & =\text { Curah hujan bulanan }(\mathrm{cm})
\end{array}
$$

Data erosivitas hujan diperoleh dari data curah hujan 10 tahun terakhir. Klasifikasi penskoran dan pembobotan erosivitas hujan seperti pada Tabel 3.

Tabel 3. Klasifikasi dan Skoring Erosivitas Hujan

\begin{tabular}{cccc}
\hline Erosivitas Hujan & $\begin{array}{c}\text { Besaran/Deskripsi } \\
(\mathrm{cm} / \text { thn })\end{array}$ & Skor & Skor x Bobot (19) \\
\hline Rendah & $<1160$ & 5 & 95 \\
Sedang & $1160-2013$ & 4 & 76 \\
Agak Tinggi & $2013-2977$ & 3 & 57 \\
Tinggi & $2977-4033$ & 2 & 38 \\
Sangat Tinggi & $>4033$ & 1 & 19 \\
\hline
\end{tabular}

Sumber: Indriastuti D, dkk (2016)

4. Erosi yang masih diperbolehkan (EDP)

EDP adalah jumlah tanah hilang yang diperbolehkan per-tahun supaya produktivitas suatu lahan tidak berkurang sehingga tanah tetap produktif secara lestari (Indrihastuti, 2016). EDP dihitung dengan persamaan dari Arsyad (2006) sebagai berikut:

$$
\begin{gathered}
\mathrm{T}(\mathrm{mm} / \mathrm{thn})=\frac{\text { Kedalaman efektif }(\text { hasil suvei }) \times \text { Nilai faktor kedalaman }(0,8)}{\text { Umur guna }(400)} \\
\mathrm{EDP}(\text { ton } / \mathrm{ha} / \mathrm{thn})=\mathrm{T} \times \mathrm{BV} \times 10
\end{gathered}
$$

Dimana:

$$
\begin{aligned}
& \text { EDP }=\text { Erosi yang diperbolehkan pada jenis tanah tertentu } \\
& \mathrm{T} \quad=\text { Nilai erosi yang diperbolehkan } \\
& \mathrm{BV}=\text { Berat Volume Tanah }\left(\mathrm{gram} / \mathrm{cm}^{3}\right)
\end{aligned}
$$

Selanjutnya hasil klasifikasi diberi skor sesuai dengan kelas kerapatan vegetasi kemudian dilakukan pembobotan. Klasifikasi penskoran dan pembobotan kerapatan vegetasi seperti pada Tabel 4.

Tabel 4. Klasifikasi dan Skoring Nilai EDP

\begin{tabular}{cccc}
\hline EDP & $\begin{array}{c}\text { Besaran/Deskripsi } \\
\text { (ton/ha/thn) }\end{array}$ & Skor & Skor x Bobot (14) \\
\hline Rendah & $<25$ & 1 & 70 \\
Sedang & $>25$ & 5 & 14 \\
\hline
\end{tabular}


Sumber: Indriastuti D, dkk (2016)

5. Erodibilitas Tanah

Data-data yang diperlukan dalam penilaian parameter erodibilitas tanah dan bobot isi tanah antara lain: tekstur tanah, presentase bahan organik, struktur tanah, permeabilitas tanah. Dimana data-data primer terkait erodibilitas tanah tersebut di atas dilakukan dengan mengambil contoh tanah di lokasi penelitian untuk kemudian dilakukan uji laboratorium. Skor, bobot dan nilai parameter erodibilitas tanah dilihat pada Tabel 5. perhitungan nilai erodibilitas (K) dihitung dengan persamaan Weiscmeier yakni:

$$
\mathrm{K}=\frac{1,292\left\{2,1 \mathrm{M}^{1,14}\left(10^{-4}\right)(12-a)+3,25(b-2)+2,5(c-3)\right\}}{100}
$$

Dimana :

$\mathrm{M}=$ Ukuran partikel (\% pasir sangat halus $+\%$ debu $\mathrm{x}(100-\%$ liat $)$

$\mathrm{a}=$ Kandungan bahan organik $(\mathrm{BO}=\% \mathrm{C} \times 1,724)$

$\mathrm{b}=$ Harkat struktur tanah

$\mathrm{c}=$ Harkat permeabilitas tanah

Tabel 5. Klasifikasi dan Skoring Erodibilitas Tanah

\begin{tabular}{cccc}
\hline Erodibilitas Tanah & Besaran/Deskripsi & Skor & Skor x Bobot (9) \\
\hline Rendah & $<0,20$ & 5 & 95 \\
Sedang & $0,21-0,32$ & 4 & 76 \\
Agak Tinggi & $0,33-0,40$ & 3 & 57 \\
Tinggi & $0,41-0,55$ & 2 & 38 \\
Sangat Tinggi & $0,56-0,64$ & 1 & 19 \\
\hline
\end{tabular}

Sumber: Indriastuti D, dkk (2016)

6. Produktivitas Lahan

Produktivitas lahan adalah rasio terhadap produksi komoditi umum optimal pada pengelolaan tradisional. Pendekatan yang digunakan untuk mengetahui tingkat produktivitas lahan adalah dengan sebuah model sebagai berikut (Ramayanti dkk, 2014).

Dimana:

$$
P v=Y / L p
$$

Y : Besarnya produksi dalam setahun (Ton)

Lp : Luas panen basis tahunan (Ha)

Pv : Tingkat produktivitas (Ton/Ha)

Untuk mendapatkan produktivitas yang dinilai berdasarkan ratio terhadap produksi komoditi umum optimal pada pengelolaan tradisional yaitu:

$$
\text { Presentase produktivitas }=\left(\frac{P v}{\text { komoditi umum }}\right) \times 100 \%
$$

Parameter produktivitas lahan dalam penentuan lahan kritis dibagi menjadi 5 kelas sesuai dengan persentase produktivitasnya berikut adalah pembagiannya.

Tabel 6 Klasifikasi dan Skoring Produktivitas Lahan

\begin{tabular}{cccc}
\hline Kelas Produktivitas & Besaran/Deskripsi (\%) & Skor & Skor x Bobot (30) \\
\hline Sangat Tinggi & $>80$ & 5 & 150 \\
Tinggi & $61-80$ & 4 & 120 \\
Sedang & $41-60$ & 3 & 90 \\
Rendah & $21-40$ & 2 & 60 \\
Sangat Rendah & $<20$ & 1 & 30 \\
\hline
\end{tabular}

Sumber: Peraturan Direktur Jenderal Bina Pengelolaan Daerah Sungai dan Perhutanan Sosial Nomor: P.4/V-SET/2013 


\section{HASIL DAN PEMBAHASAN}

\section{Faktor yang mempengaruhi Tingkat Kekritisan Lahan DAS Jenerakikang}

Berubahnya kemampuan lahan untuk berproduktivitas adalah salah satu indikator dari timbulnya lahan kritis. Timbulnya lahan kritis disebabkan oleh beberapa faktor, diantaranya yakni sebagai berikut:

1. Topografi

Unsur-unsur topografi yang paling berpengaruh terhadap timbulnya lahan kritis adalah kemiringan lereng. Tidak hanya itu saja panjang lereng, bentuk dan arah lereng dapat mempengaruhi terjadinya erosi yang merupakan cikal-bakal pula terjadinya lahan kritis. Semakin panjang lereng, maka jumlah erosi total akan semakin banyak.

2. Tanah

Tanah sebagai suatu sistem dinamis selalu mengalami perubahan dari waktu ke waktu. Perubahan dari segi fisika, kimia maupun biologi tanah yang berlebihan akan menimbulkan degradasi pada tanah.

Kedalaman tanah efektif berpengaruh terhadap kepekaan tanah pada erosi. Tanah-tanah yang dalam dan permeabel kurang peka terhadap erosi daripada tanah yang permeabel tetapi dangkal.

3. Erosi

Erosi adalah peristiwa yang terjadi akibat adanya interaksi kerja antara faktor-faktor iklim, topografi, sifat-sifat tanah, tumbuh-tumbuhan (vegetasi), dan perlakuan manusia terhadap tanah. Faktor iklim yang berpengaruh terhadap erosi adalah hujan. Curah hujan dalam suatu waktu mungkin tidak menyebabkan erosi jika intensitasnya rendah. Demikian pula apabila hujan dengan intensitas tinggi tetapi terjadi dalam waktu singkat. Hujan akan menimbulkan erosi jika intensitasnya cukup tinggi dan jatuhnya dalam waktu yang relatif lama.

4. Vegetasi

Vegetasi mempunyai peranan penting dan sangat berpengaruh terhadap erosi di suatu tempat. Dengan adanya vegetasi tanah dapat terlindung dari bahaya kerusakan tanah oleh butiran hujan. Selain itu, vegetasi menjadi penanda apakah lahan tersebut tergolong kritis, jika vegetasi penutup lahannya baik atau produktif maka dapat dijadikan asumsi awal bahwa lahan tersebut tidak kritis, begitupun sebaliknya.

\section{Tingkat Kekritisan Lahan}

Hasil analisis lahan kritis di DAS Jenerakikang tahun 2019 dengan parameter modifikasi P.4/V-SET/2013 seluas 299,104 Ha (1,12 \% dari total luas wilayah DAS Jenerakikang), secara rinci disajikan pada Tabel 7 dan sebaran lahan kritis dapat dilihat pada Gambar 2.

Tabel 7. Luas Lahan Kritis DAS Jenerakikang Tahun 2019

\begin{tabular}{ccccccc}
\hline \multirow{2}{*}{ No } & Kawasan & \multicolumn{3}{c}{ Tingkat Kekritisan Lahan } & \multirow{2}{*}{ Total } \\
\cline { 3 - 6 } & \multirow{2}{*}{ Kritis } & $\begin{array}{c}\text { Agak } \\
\text { Kritis }\end{array}$ & $\begin{array}{c}\text { Potensial } \\
\text { Kritis }\end{array}$ & $\begin{array}{c}\text { Tidak } \\
\text { Kritis }\end{array}$ & \\
\hline \multirow{2}{*}{1} & $\begin{array}{l}\text { Kawasan Lindung di } \\
\text { Luar Kawasan Hutan }\end{array}$ & 1,045 & 136,661 & 718,413 & 56,229 & 912,348 \\
2 & Budidaya Pertanin & 299,059 & 1072,064 & 1761,757 & 158,909 & 3290,79 \\
\hline & Total (Ha) & 299,104 & 1208,725 & 2480,17 & 215,138 & 4203,14 \\
\hline & 7,12 & 28,76 & 59,01 & 5,12 & 100 \\
\hline
\end{tabular}

Sumber: Hasil analisis DAS Jenerakikang parameter modifikasi P.4/V-SET/2013 


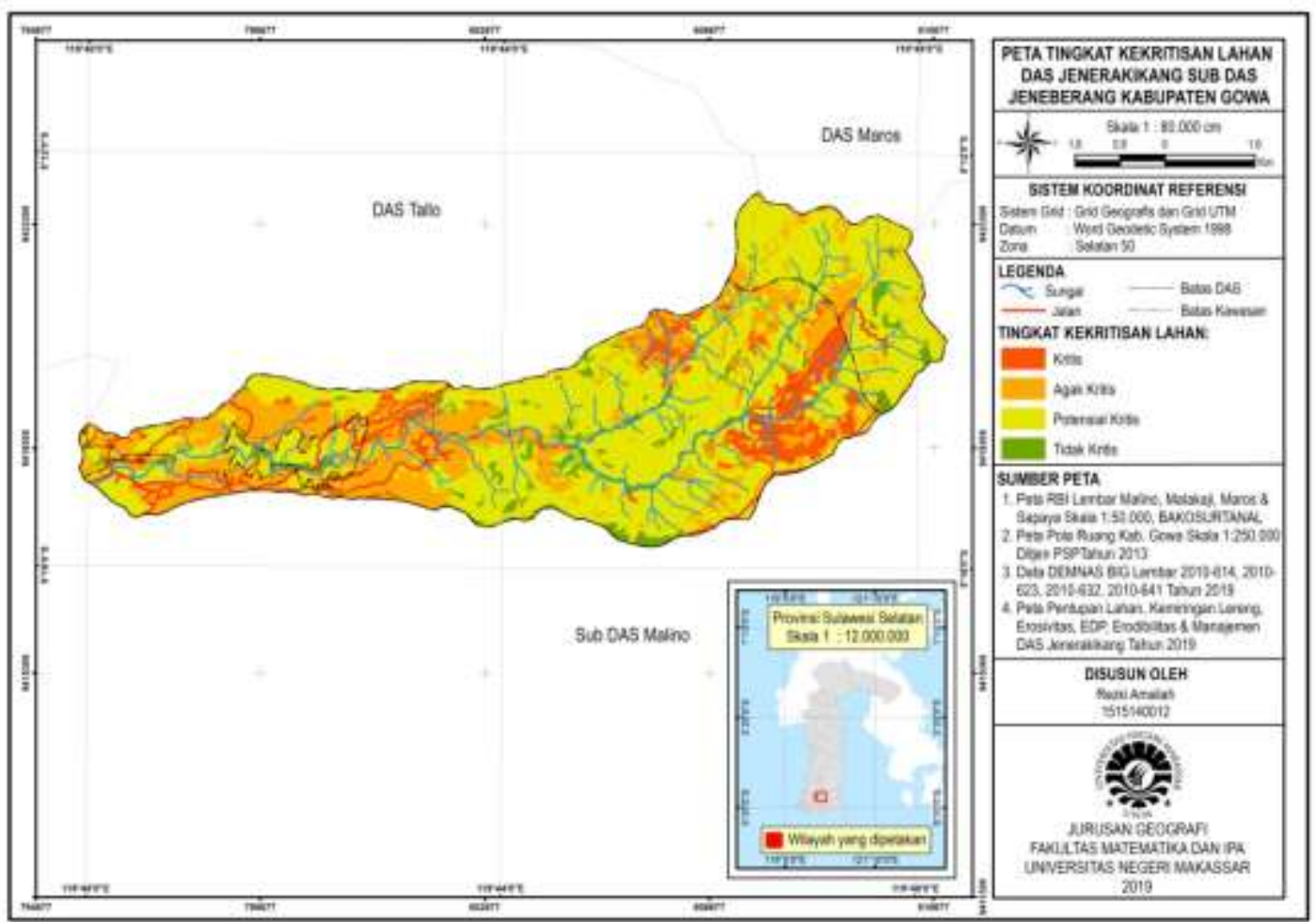

Gambar 2. Peta Lahan Kritis DAS Jenerakikang Tahun 2019

\section{Upaya Penanggulangan Kekritisan Lahan DAS Jenerakikang}

\section{a. Metode Fisik - Mekanik}

Pengendalian erosi secara teknis mekanis adalah usaha-usaha pengawetan tanah untuk mengurangi banyaknya tanah yang hilang di daerah lahan pertanian dengan cara-cara mekanis. Usaha pengendalian erosi secara teknis mekanis berupa bangunan-bangunan teknis pada lahan yang miring, berupa teras dan saluran pembuangan air.

Usaha konservasi metode mekanik pada DAS Jenerakikang dapat dilihat penerapannya pada penggunaan lahan sawah, terlihat di beberapa jenis penggunaan lahan sawah yang menjadi titik observasi menerapkan model terasering pada sawah dengan kemiringan yang cukup terjal.

\section{b. Metode Biologis/Vegetatif}

Metode vegetatif yaitu tindakan dengan melakukan penanaman berbagai jenis tanaman. Fungsi tanaman untuk melindungi tanah terhadap daya tumbukan buti-butir air hujan, melindungi tanah terhadap daya perusak aliran air di atas permukaan dan memperbaiki penyerapan air oleh tanaman. Beberapa cara yang dapat dilakukan dalam usaha konservasi tanah secara vegetasi adalah: rnanaman majemuk (Multiple Cropping), pergiliran tanaman (Crop Rotation), tumpang sari (Intercropping), Mulsa, dan lain-lain.

Penerapan metode biologis di DAS Jenerakikang dapat dilihat pada penggunaan lahan kebun campuran yang ditanami berbagai macam vegetasi, seperti tanaman kopi yang diselingi dengan berbagai macam vegetasi lainnya.

\section{SIMPULAN DAN SARAN}

Kesimpulan yang dapat diambil pada penelitian ini adalah: (1) Faktor yang mempengaruhi tingkat kekritisan lahan adalah topograafi, tanah erosi dan vegetasi (2) DAS Jenerekakikang memiliki 4 kategori lahan kritis yakni tingkat lahan kritis memiliki luas lahan 324,02 Ha, tingkat lahan agak kritis memiliki luas 2.734,1 Ha, tingkat lahan potensial kritis memiliki luas 1.088,8 Ha, tingkat lahan tidak kritis memiliki luas 56,229 Ha. (3) Metode yang digunakan dalam upaya penanggulangan lahan kritis, 
yaitu metode fisik - mekanik (penerapan terasering) dan metode biologis/ vegetatif (penerapan Multiple Cropping).

Perlu adanya analisis tingkat kekritisan lahan di berbagai wilayah dengan memanfaatkan Sistem Informasi Geografi (SIG), agar analisis tersebut dapat digunakan untuk penyusunan informasi luas lahan kritis yang digunakan sebagai masukan bagi perencanaan upaya konservasi dan rehabilitasi lahan untuk pengembangan wilayah maupun penyempurnaan tata ruang wilayah. Memberdayakan masyarakat untuk mengenali lahan yang tidak produktif serta sosialisasi ke masyarakat mengenai upaya penanggulangannya.

\section{DAFTAR RUJUKAN}

Argo, Yanuar. 2014. Penentuan Prioritas Penanganan Lahan Kritis di Kabupaten Sukabumi. Jurnal Widyariset. Vol.17, No.2: 251-258.

Fatir, M, Darwin.2019. WALHI Sebut Kawasan DAS Jeneberang Berstatus Kritis. https://makassar.antaranews.com/berita/1 10490/walhi-sebut-kawsan-das-jeneberangberstatus-kritis diakses pada tanggal 28 Mei 2019 pukul 10.30 WITA.

Indrihastuti, D., Murtilaksono, K., Tjahjono, B. 2016. Analisis Lahan Kritis dan Arahan Rehabilitasi Lahan dalam Pengembangan Wilayah Kabupaten Kendal Jwa Tengah. Jurnal Tata Loka. Vol.18, No.3: 141-156.

Renyut, L.R., Kumurur, V.A., Karongkong, H.H. 2018. Identifikasi dan Pemetaan Lahan Kritis dengan menggunakan Teknologi Sistem Informasi Geografis (Studi Kasus Kota Bitung). Jurnal Spasial. Vol.5, No.1.

Sylviani \& Yosefi, E. 2010. Potensi dan Pemanfaatan Sumberdaya Air di Daerah Aliran Sungai Jeneberang dan Kawasan Hutan Lindung (Studi Kasus di Kabupaten Gowa, Provinsi Sulawesi Selatan). http://kelembagaandas.wordpress.com/kelembagaan-pengelolaansda/sylviani-dan-elfida-yosefi-s/ diakses pada tanggal 28 Mei 2019 pukul 10.45 WITA. 